\title{
Pathological Findings in Accidental Electrocution in a Horse (Case Report)
}

\author{
Adrian Florin GAL, Viorel MICLĂUȘ, Flaviu TĂBĂRAN*, Marian TAULESCU, Andras NAGY, Roxana CORA, \\ Vasile RUS, Cornel CĂTOI
}

Faculty of Veterinary Medicine, University of Agricultural Sciences and Veterinary Medicine, 3-5

Mănăştur Street, 3400 Cluj-Napoca, Romania

*corresponding author: alexandru.tabaran@usamvcluj.ro

Bulletin UASVM Veterinary Medicine 73(2) / 2016,

Print ISSN 1843-5270; Electronic ISSN 1843-5378

DOI:10.15835/buasvmcn-vm: 12164

\begin{abstract}
Recently, the veterinarians are dealing with a number of cases that require forensic expertise. Such a circumstance could be the accidental electrocution in animals, one of the causes of unnatural death. There is a scarcity with reference to the pathological findings in veterinary forensic medicine. In this paper, we present the main lesions that occurred in a horse with accidental electrocution that was presented for complete necropsy survey. A horse corpse was sent to the Pathology Department (Faculty of Veterinary Medicine, Cluj-Napoca, Romania) for a full medical survey. Preliminary results and external examination: the body was in rigor mortis; from the nasal cavities drained out reddish foam and in the mouth was observed the presence of ingested feed (straw) that was not chewed, suggesting a quick death. The findings detected after internal examination of the carcass were poor blood coagulability, haemorrhagic diathesis throughout the body, with haemorrhages of various sizes in different body regions (e.g., muscles of the withers, in the gluteal muscle, the mucosa of epiglottis, larynx, trachea, in the interstitium of the lung, and ecchymosis in the left kidney). Some other lesions detected were infarcts and haemorrhages in the fundic region of the stomach's mucosa. In electrocution, haemorrhages are most often located in the respiratory tract, aspect observed in our case too. However, the diagnosis of electrocution has to corroborate the necropsy findings (which are not specific), with some other data such as the fulminant death and inspection of power source.
\end{abstract}

Keywords: electrocution, forensic medicine, horse, accident.

\section{INTRODUCTION}

Electrical injuries in animals take place most often by accident. They include contact to a number of forms of currents, comprising rotary, alternating, or direct currents. Dependent on several parameters of the current (e.g., the voltage, type of circuit, current and period of exposure) and a number of details concerning the animal (e.g., dry or wet hair coat and passageway of current through the body), gross lesions may be absent or may be inconclusive (Munro and Munro, 2008; Schulze et al., 2016). They can include early or localized expansion of rigor mortis marks of acute circulatory failure or deep thermo electrical burns. Such burns type may display as external current marks, metallization of the skin, burned hair or feathers, or sporadically internal electroporation damage resulting in muscle necrosis, vascular damage with thrombosis, hemolysis, injury to spinal cord and brain, or skeletal fractures. Additionally, lightning strikes take place on a regular basis in grazing animals, which have higher risk of death from step potentials (i.e., ground current) along with direct strike and contact injury. In such 


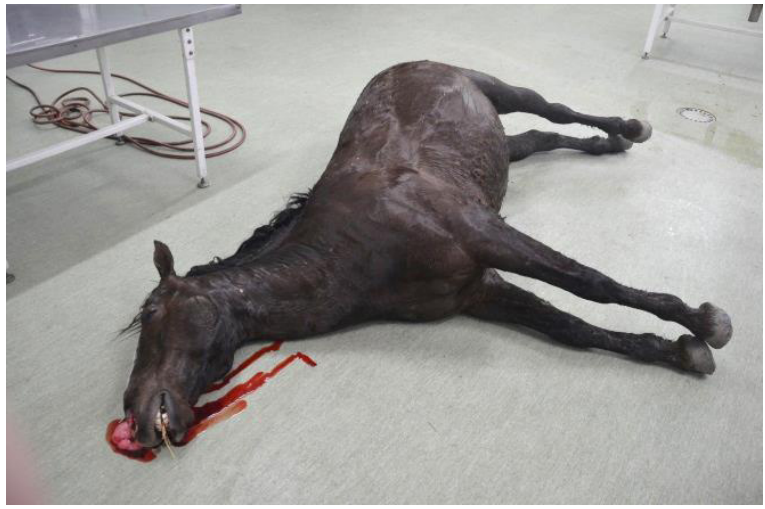

Fig. 1. The horse corpse in rigor mortis with a bunch of

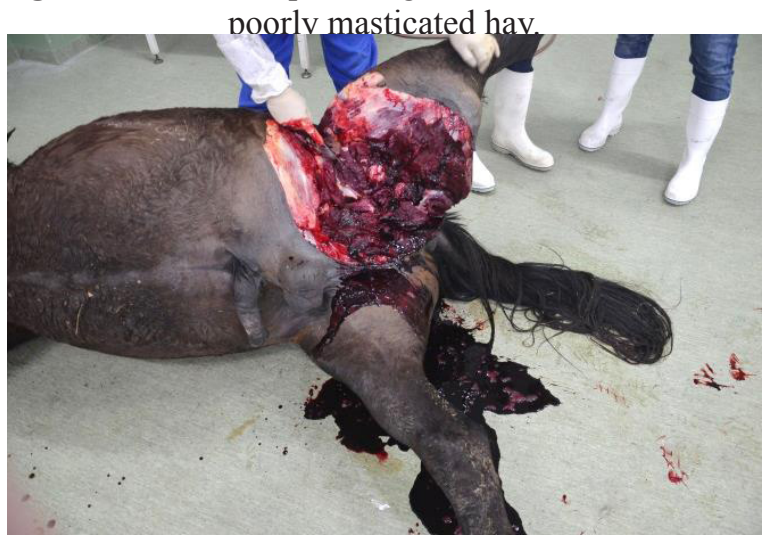

Fig. 3. Poorly coagulated blood, and extensive haemorrhages in the muscle of rear leg.

circumstances, the subject involved may have no lesions, external signs of punctate or linear burns, keraunographic markings, or exit burns on the soles of the coronary bands or the hooves. Besides detailed evidence about the surroundings at the location where the subject was found, electrical damages in animals necessitate a comprehensive morphological workup, as well as additional investigations in combination with certain data about the conceivable lesion spectrum (Munro and Munro, 2008; Schulze et al., 2016).

Since these cases do not occur regularly in diagnostic pathology, they represent a thought-provoking task in general but also with regard to forensic or criminal features (i.e., whether a lesion represents a nonaccidental or accidental consequence). Besides an exhaustive information about the circumstances at the site, thermal damages in animals necessitate a detailed morphological assessment, including supplementary investigations in combination with a deep knowledge concerning the possible lesion variety and appropriate supplementary

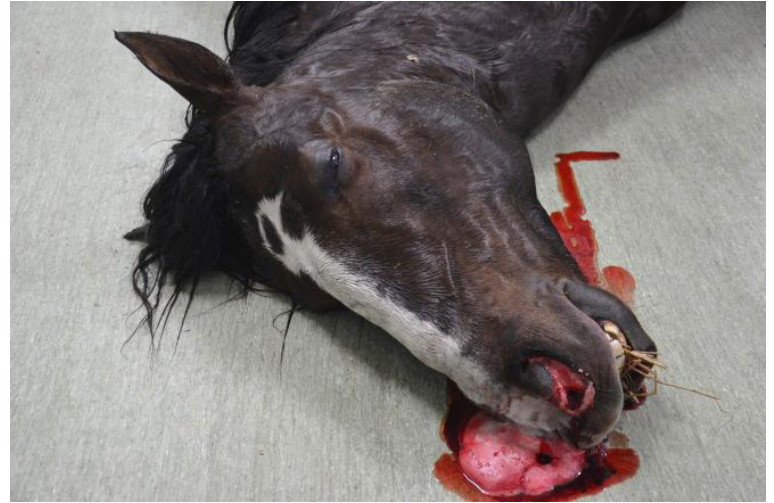

Fig. 2. Discharge of reddish foamy material from nasal

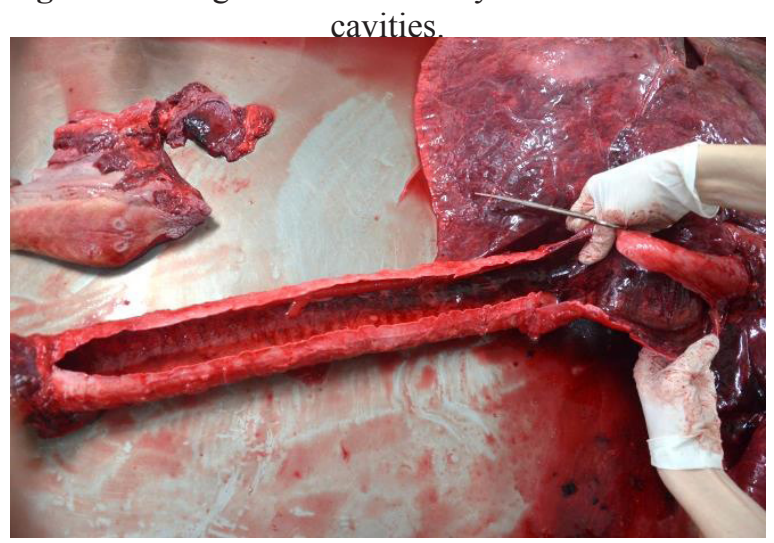

Fig. 4. Petechiae and suffusions in the mucosa of the upper respiratory tract.

investigations (Munro and Munro, 2008; Wohlsein et al., 2016).

Recently, the veterinarians are dealing with a number of cases that require forensic expertise. Such a circumstance could be the accidental electrocution in animals, one of the causes of unnatural death. There is a scarcity with reference to the pathological findings in veterinary forensic medicine. In this paper, we present the main lesions that occurred in a horse with accidental electrocution that was presented for complete necropsy survey.

\section{MATERIALS AND METHODS}

A horse corpse was sent to the Pathology Department (Faculty of Veterinary Medicine, ClujNapoca, Romania) for a full medical survey. The recorded case had the following details: 8 years old male horse, mixed breed. Following the gross examination of the carcass, tissue samples were collected, fixed in $10 \%$ buffered formalin and routinely processed for histology. From paraffin blocks, 5-micron thick sections were obtained and 
stained with Hematoxylin-eosin (HE). Histologic examination was performed using the Olympus BX51 microscope connected to a digital camera (Olympus DP-25).

\section{RESULTS AND DISCUSSION}

The gross examination of the corpse included preliminary results (concerning the mode of presentation, state of the body and external exam) and internal exam.

Preliminary results/external exam revealed the following: the corpse was brought for forensic expertise in rigor mortis (Fig. 1), and the animal laid on the right side (aspect suggested by the cadaveric hypostasis). The nasal cavities displayed a reddish foamy material (Fig. 2), while in the mouth was found a bunch of poorly masticated hay (aspect that may suggest a sudden death, Fig. 1). On some regions of the body were noticed hairless areas likely created by harnesses. No carbonised areas were identified on the skin, mouth, legs (i.e., the possible contact area with the electric power source).

Internal exam revealed the next findings: poorly coagulated blood and haemorrhagic diathesis throughout the carcass (Fig. 3), reflected by petechiae to larger suffusions. Accordingly, suffusions and blood collections were detected on the right dorsolateral side of the withers, in the left gluteal muscle. Petechiae and suffusions were noticed in the mucosa/submucosa of the epiglottis, larynx and trachea (Fig. 4), together with a large amount of pinkish foam in the upper respiratory tract. Bilateral interstitial haemorrhages occurred in the lung, but more prominent in the anteroventral lung lobes. Some other haemorrhages were noticed in the renal cortex, while the fundic region of the stomach displayed red infarcts and petechiae. Some other lesions displayed by the carcass that could be the consequence of the cardiac arrest were hydropericardium, hydrothorax, ascites, lung oedema and haemorrhages. All liquids noticed in the pericardial, thoracic and abdominal cavities had a reddish (haemorrhagic) aspect.

Other lesions that had no relations with electrocutions were: chronic ulcerative parasitic gastritis (visible Gasterophilus spp. attached to the oesophagogastric mucosa), chronic parasitic typhlitis (parasitism with Anaplocefala spp. tapeworms), chronic adhesive perihepatitis, multifocal parasitic granulomatous hepatitis, chronic adhesive pleuritis, and foci of chronic fibrous pleuritis (involving the visceral pleura of the diaphragmatic lung lobes).

Electrical current that is measured in amperes is the energy responsible for the elaboration of heat following the passage through a conductor. Since the current flows from one connection point to another, the contact points may display the greatest tissue damages. Injuries to profounder organs can be occasional and random. The tissue injuries depend on exposure time to electrical current (i.e., a longer contact with current is often associated with more severe injuries as a consequence of a greater generation of heat). In some species (e.g. puppies and hamsters), burns can be detected to the lips and mouth following chewing through the insulation of power cables in the home. As a comparison, burns created by live electricity cables in the home are usually less severe than the damages associated with highvoltage cables. As a general principle, when hair and skin are dry (and electrical resistance is high), more heat is produced and the probability of burns is augmented (Munro and Munro, 2008).

Concerning the mechanism of death, lethal electrocution is usually a consequence of the current passing through the head and/or body triggering cardiac arrest and/or injury to vital cerebral centres. Since the body is a superior conductor of electricity than the ground, the electrical current will preferentially enter the body frequently through one foot, departing through another. The foot nearer to the electrical source has a potential difference with the other feet. Accordingly, a greater potential difference is associated with a greater risk to the animal. Because of the distance between front and hind feet, large animals (e.g., cattle and horses) may present a higher risk following exposure to electricity than smaller animals (Novales et al., 1998;-Ozmen et al., 2007; Munro and Munro, 2008).

The main post-mortem findings that may occur following electrocution are diverse. It is mostly agreed that rigor mortis progresses quickly and passes off rapidly in electrocuted animals and is escorted by quicker post-mortem decomposition (Radostits et al, 2007; Anon, 2005;-Munro and Munro, 2008). Congestion and petechiae may arise all over the body, but they may be predominantly noticeable in the upper respiratory tract. The 
blood may be unclotted and dark. In some species such as pigs, the muscular spasm following electrocution may induce fractures of femur, pelvis bones and lumbosacral vertebrae (Nevelös et al., 1967; Bildfell et al., 1991; Van Alstine et al., 2003). In some corpses the pathological findings could be discreet, with few indications concerning the cause of death. In such circumstance the diagnosis of electrocution will count on exclusion of other causes (e.g. infectious diseases, chemical poisoning etc.), and on other signs (e.g., sudden death, confirmation of an electrical fault; Munro and Munro, 2008).

\section{CONCLUSION}

In electrocution haemorrhages are most often located in the respiratory tract (Munro and Munro, 2008), aspect observed in our case too. In our subject, the main internal and external findings that may suggest electrocution were: unclotted aspect of the blood, haemorrhagic diathesis particularly in the upper respiratory tract (i.e., mucosa of the epiglottis, larynx and trachea), the presence in the mouth of a bunch of poorly masticated hay (suggesting a sudden death). However, the diagnosis of electrocution has to corroborate the necropsy findings (which are not specific), with some other data such as the fulminant death and inspection of power source (Munro and Munro, 2008).

\section{REFERENCES}

1. Anon (2005). Lightning stroke and electrocution: introduction. In: Kahn CM, ed. The Merck veterinary manual. Whitehouse Stations, NJ, p. 529-530.

2. Bildfell RJ, Camat BD, Lister DB (1991). Posterior paralysis and electrocution of swine caused by accidental electric shock. J Vet Invest 3:364-367.

3. Munro HM, Munro R (2008). Animal abuse and unlawful killing: forensic veterinary pathology. Elsevier Health Sciences, 70-74.

4. Nevelös A, Rózsa G, Somogyi E, Sótonyi P, Varga T (1967). Lesions of skeletal muscles following electrocution. Acta Med Leg Soc (Liege) 20(2):203-206.

5. Novales M, Hermandez E, Lucena R (1998). Electrocution in the horse. Vet Rec 142:68.

6. Ozmen 0, Haligur M (2007). Heart lesions following accidental electrocution of dairy cattle. Vet Rec 161(7):240-241.

7. Radostits OM, Gay CC, Hinchcliff KW et al. (2007). Diseases associated with physical agents. In: Veterinary medicine, 10th edn. Edinburgh: Saunders Elsevier, p. 1785-1795.

8. Schulze C, Peters M, Baumgärtner W, Wohlsein P (2016). Electrical Injuries in Animals Causes, Pathogenesis, and Morphological Findings. Veterinary pathology, 0300985816643371.

9. Van Alstine WG, Widmer WR (2003). Lightning injury in an outdoor swine herd. J Vet Diagn Invest 15(3):289-291.

10. Wohlsein P, Peters M, Schulze C, Baumgärtner W (2016). Thermal injuries in veterinary forensic pathology. Veterinary pathology, 0300985816643368. 